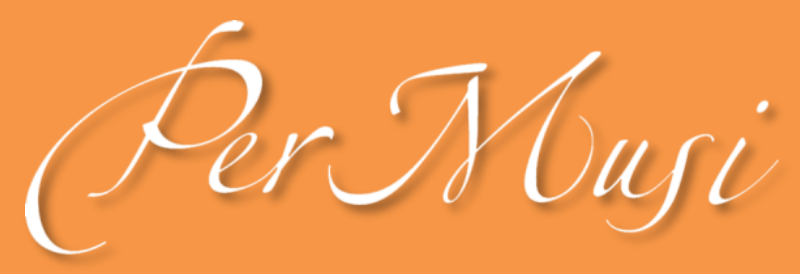

eISSN 2317-6377

\title{
Exploring pedagogical strategies for piano sight-reading
}

\author{
Marcelo Almeida Sampaio \\ https://orcid.org/0000-0002-5713-3213 \\ Universidade do Estado de Minas Gerais \\ marcelo.sampaio@uemg.br \\ Patricia Furst Santiago \\ https://orcid.org/0000-0002-5029-5623 \\ Universidade Federal de Minas Gerais \\ patfurstsantiago@gmail.com
}

SCIENTIFIC ARTICLE

Submitted date: 26 mar 2020

Final approval date: 09 apr 2021

\begin{abstract}
In a piano sight-reading (SR) experiment, 27 undergraduate students had their SR measured. It tested the hypothesis that transposition (control group) would be a pedagogical intervention better than rhythmic training and the use of four-handed repertoire (two experimental groups). The individual errors were collected from three tests in three difficulty levels ( 27 students $\times 3$ tests $\times 3$ levels), generating a total of 243 observations. Although students improved their performance by $30 \%$, none of the pedagogical interventions had any significant effect $(p=0.96)$. The results were: a) practicing reading in the bass clef, the rhythmic aspects more than the melodic ones, and the left hand more than the right one, brings more benefits to the piano SR performance; b) isolated SR strategies has little effect on students development; c) using a hybrid curriculum matrix with three or more significant predictors seems to be the most appropriate way to develop a SR competency.
\end{abstract}

Keywords: Piano sight-reading; Pedagogical strategies; Experiment; Generalized linear models.

\section{TíTULO: EXPLORANDO AS ESTRATÉGIAS PEDAGÓGICAS PARA A LEITURA À PRIMEIRA VISTA AO PIANO}

Resumo: Em um experimento de leitura à primeira vista (LPV) ao piano, 27 estudantes de graduação foram testados a partir da hipótese de que a transposição (grupo controle) seria uma intervenção pedagógica melhor que o treinamento rítmico e o uso do repertório a 4 mãos (grupos experimentais). Os erros foram computados em três testes em três níveis de dificuldade (27 estudantes $\times 3$ testes $\times 3$ níveis), gerando um total de 243 observações. Apesar de os estudantes melhorarem seu desempenho em $30 \%$, nenhuma das intervenções teve efeito significativo ( $p=0,96)$. Como resultados: a) exercitar a leitura na clave de fá, os aspectos rítmicos mais que os melódicos e a mão esquerda mais que a direita traz melhores resultados para a LPV; b) estratégias isoladas têm pouco efeito nos alunos; c) usar uma matriz curricular híbrida com três ou mais preditoras significativas parece ser o melhor caminho pedagógico.

Palavras-chave: Leitura à primeira vista ao piano; Estratégias pedagógicas; Experimento; Modelos lineares generalizados. 


\section{Exploring pedagogical strategies for piano sight-reading}

Marcelo Almeida Sampaio, Universidade do Estado de Minas Gerais, marcelo.sampaio@uemg.br Patrícia Furst Santiago, Universidade Federal de Minas Gerais, patfurstsantiago@gmail.com

\section{Introduction ${ }^{1}$}

The process of deciphering the musical score is a challenge for all pianists, from the very beginning of reading music to the most advanced level, when the metaphorical, interpretative, symbolic and artistic knowledge subtended in music fuse together and become more complex. Therefore, music sight-reading (SR) is a prime competence for the training of solo and collaborative pianists, chamber musicians, rehearsers, arrangers, composers and conductors.

We define sight-reading as the musical perception of a score, cognitively processed, and externalized in sounds, from a motor behaviour in a performance without rehearsal or prior reading ${ }^{2}$. SR is a competence that requires hight cognitive and physical performance. Its action requires energy consumption in the processing of several interdependent layers as follows:

a) generic cognitive: in attention, perception and memory;

b) visual cognitive: in the recognition of the pitches and their relation to learned musical patterns;

c) auditory cognitive: listening to pitches and their identification with the writing of the score;

d) motor cognitive: in the coordination between the movement of the eyes, hands and feet and what is read.

Research points out that rhythmic training improves performance in SR (Halsband et al. 1994; Zhukov 2014b). Rhythmically accurate students tend to be more fluent in reading notes. But the opposite is not true: correct reading of notes does not guarantee rhythmic accuracy. In general, rhythm perception also increases the efficiency of motor tasks that require accurate planning of physical movements (Halsband et al. 1994, 265). Piano motor skill is a direct physical response to mental perceptions; consequently, changes in perception would lead to changes in motor responses in the same way (Halsband et al. 1994, 267). In research on rhythmic SR training, several findings are important:

\footnotetext{
${ }^{1}$ This article presents a doctoral research on piano sight-reading (SR) entitled Pedagogical strategies to piano sight-reading, conducted in the post-graduate programme of the Federal University of Minas Gerais, Brazil (Sampaio 2017).

2 Preliminary reading: "careful observation of the score before it is played or sung and the performance, outside the instrument, of certain score structures by means of solfege and rhythm in combined action" (Ramos 2005, 2).
} 
(a) a greater emphasis on rhythmic training can have positive effects on students' SR as a whole, as rhythmic training improves overall flow and continuity of piano playing (Zhukov 2014a, 73);

(b) there is a direct effect between the shaping of motor patterns skills and the perception of rhythmic grouping, confirming the hypothesis that the way a person perceives musical notation - by isolated pitches, articulated motive patterns or by metric grouping over time - is reflected in motor patterns skills, especially wrist movement (Halsband et al. 1994, 281).

Another variable that supports the development of piano SR is the practice of playing together and collaborating with other musicians and singers. The experiments of Watkins (1984), Watkins \& Hughes (1986), and Lehmann et al. (1996) have yielded important results: when teaching SR, problems with rhythmic accuracy can be solved in a group performance situation, especially when accompanying another musician. Such a practice can also be done, for example, by accompanying a recording of a soloist (Watkins 1984, 7172). Because most musicians understand rhythmic accuracy as the basis for good SR, it is possible that reading accuracy in terms of pitches and expression may be improved by the use of accompaniment as a teaching tool (Watkins and Hughes 1986, 98). The advantage of this practice is that the student is required to maintain a steady rhythm and reading with the beat, as opposed to a common playing situation with continuous interruptions for error correction and adjustments. Maintaining steady flow is essential in this situation, forcing students to often sacrifice the correct pitches in order to stay integrated with flow and tempo.

Considering the challenges that SR presents to pianists, this article offers a synthesis of research on the subject (Sampaio 2017), aiming to verify the hypothesis that transposition is a more effective pedagogical intervention for the development of piano SR than rhythmic training and the use of four-handed repertoire. The variables measured in this research - transposition, four-handed repertoire and rhythmic training - were chosen from the literature review which included the analysis of SR methods for piano and a significant body of research. This literature review showed that, unlike rhythmic training and four-handed repertoire, transposition was not previously measured in experiments by researchers. Thus, the choice of transposition as an independent variable in this research is due to its possible relevance in the practice of SR classes.

Predictor variables measured in the research were: (a) Test - Test 1, before training, Tests 2 and 3 after training); (b) Level - referring to students' SR difficulty levels at 1= Easy, 2= Medium, and 3= Hard); (c) Harmony - if the students were aware of the harmonic functions; (d) Instrument - which instrument the students play -, in this experiment we had singing, guitar, violin, tuba, trumpet, harp, trombone, and (e) Weekly Study Average - if students studied more than four times a week.

\section{Research Design}

This study involved an experiment with twenty-seven undergraduate volunteer students from the second period, coming from the two Music Degree courses with qualification in School Music Education located at the State University of Minas Gerais (UEMG), in Belo Horizonte, Brazil. Those twenty-seven students did not have the piano as major in undergraduate courses. They were approved prior to their participation in this research, in compulsory subjects of the curriculum that taught electronic keyboard. Students were randomly allocated to two control groups, which tested SR with rhythmic training and the use of four-handed repertoire; and one experimental group, which tested SR with transposition. The design of the experiment was divided into three phases, broken down as follows in Figure 1. 


\section{- Phase 1: Pre-test}

In this phase, the students answered a questionnaire and an interview. The Pre-test was made from the SR performance of six $\mathrm{ABRSM}^{3}$ Specimen music pieces, levels 1, 2 and 3, respectively, easy, medium and difficult. Students listened to a standard recording explaining the procedures to be performed at the time of the test.
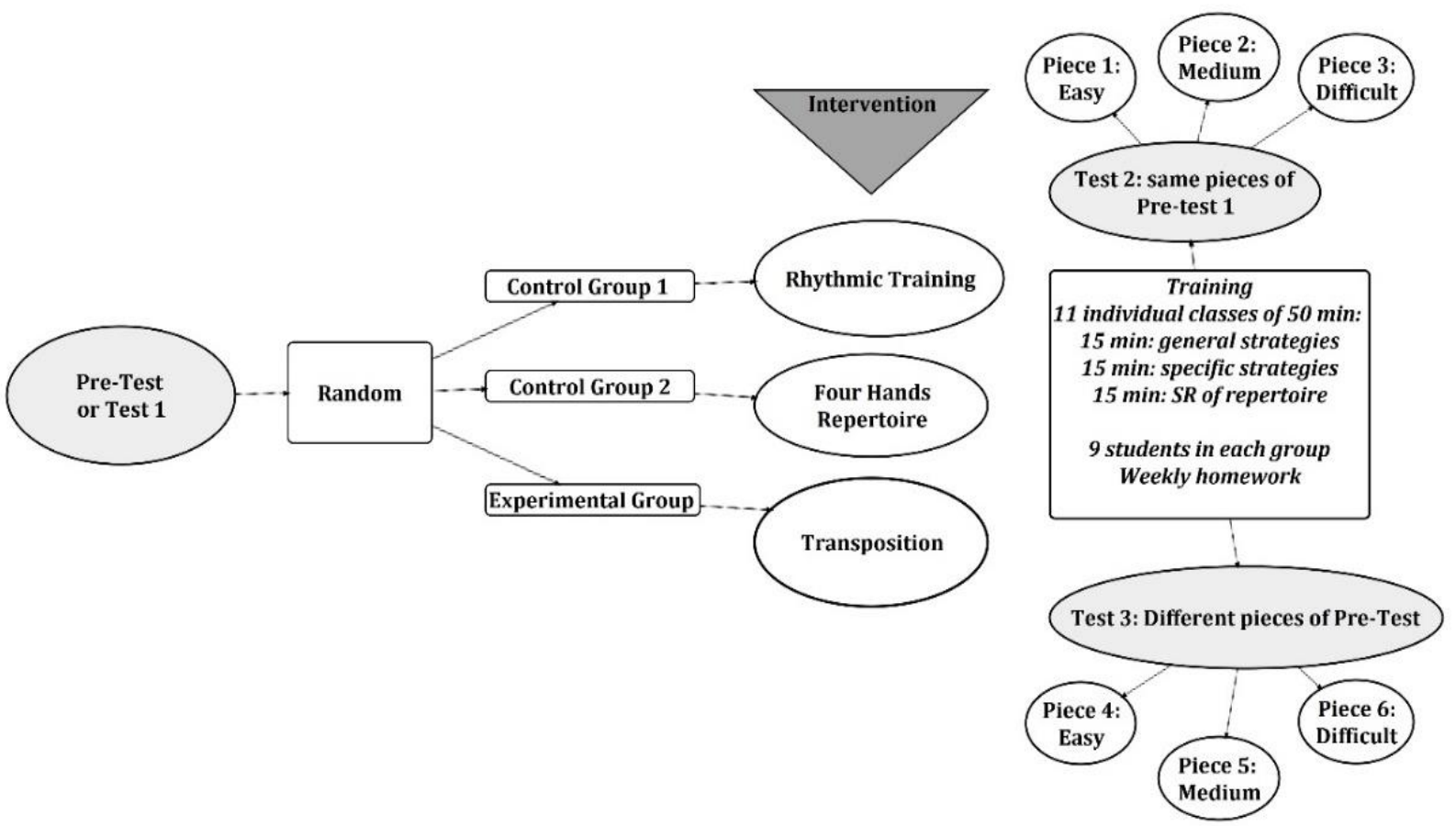

Figure 1 - Experimental design.

Then they performed an easy piece (level 1) to familiarize themselves with the process of playing, being filmed, and locating themselves on the keyboard. This piece could be repeated as many times as necessary, so students could fully understand how to perform the test. Then the students performed the other six pieces, with a $60 \mathrm{bpm}$ metronome for all the pieces, with a break just to turn the page to be read. The quality of execution in terms of phrasing, dynamics, agogic and expressiveness was not considered in order to have fewer variables to measure. Pre-test performances were filmed and recorded and their errors quantitatively measured.

\section{- Phase 2: Training}

At this stage, the students underwent to a SR training over three months. The training took place from August to November 2016, at the UEMG School of Music, in a room with acoustic piano. Students were randomized in three groups, two control groups and one experimental group. In Control Group 1, the students performed rhythmic training as a pedagogical intervention. Such training consisted of hands, feet and body practice, rhythmic exercises and various combinations of the hands from a fixed beat. In Control Group 2, the intervention focused on a four-handed piano repertoire played with the teacher. In the Experimental Group, the focus was on transposing melodies of the right and left hands into neighbouring tones, usually one semitone above and below the original one. This transposition was performed at first sight, based only on touch and visual perception of the score, without previous rehearsal.

\footnotetext{
${ }^{3}$ Associated Board of the Royals Schools of Music.
} 


\section{- Phase 3: Post-tests 2 and 3}

In this phase, the students submitted to Tests 2 and 3, answered to questionnaire 2 and interview 2 . Tests 2 and 3 were done at the same time, from the execution of six musical pieces. In Test 2, they read the same six pieces of ABRSM Specimen Test 1, levels 1, 2, and 3 respectively, easy, medium, and hard. In Test 3, the students also read six other completely different pieces at the three difficulty levels to investigate whether there were other differences from the first test and the second one. In these tests, students were evaluated on the same criteria for errors of pitch, rhythm and hesitation, again disregarding musical aspects such as phrasing, dynamics, agogic and expressiveness. The Pre and Post-tests performances were filmed and recorded and their errors were quantitatively measured.

\section{Data analysis of Generalized Linear Models: modelling, results and discussions}

\section{1 - Generalized Linear Models}

For the statistical analysis process, the Generalized Linear Models (GLMs) technique was used. In statistics, GLMs are a flexible generalization of ordinary square least regression. They relate the random distribution of the response variable in the experiment (the distribution function) to the systematic part (non-random or linear predictor) through a function called the binding function.

The modelling of errors of sight-reading (SR) was detailed from the Generalized Estimation Equations (EEGs) of the predictor variables collected in the questionnaires and tests performed. Graph 1 shows the ratio of each response variable to the total of errors and errors committed in each hand.

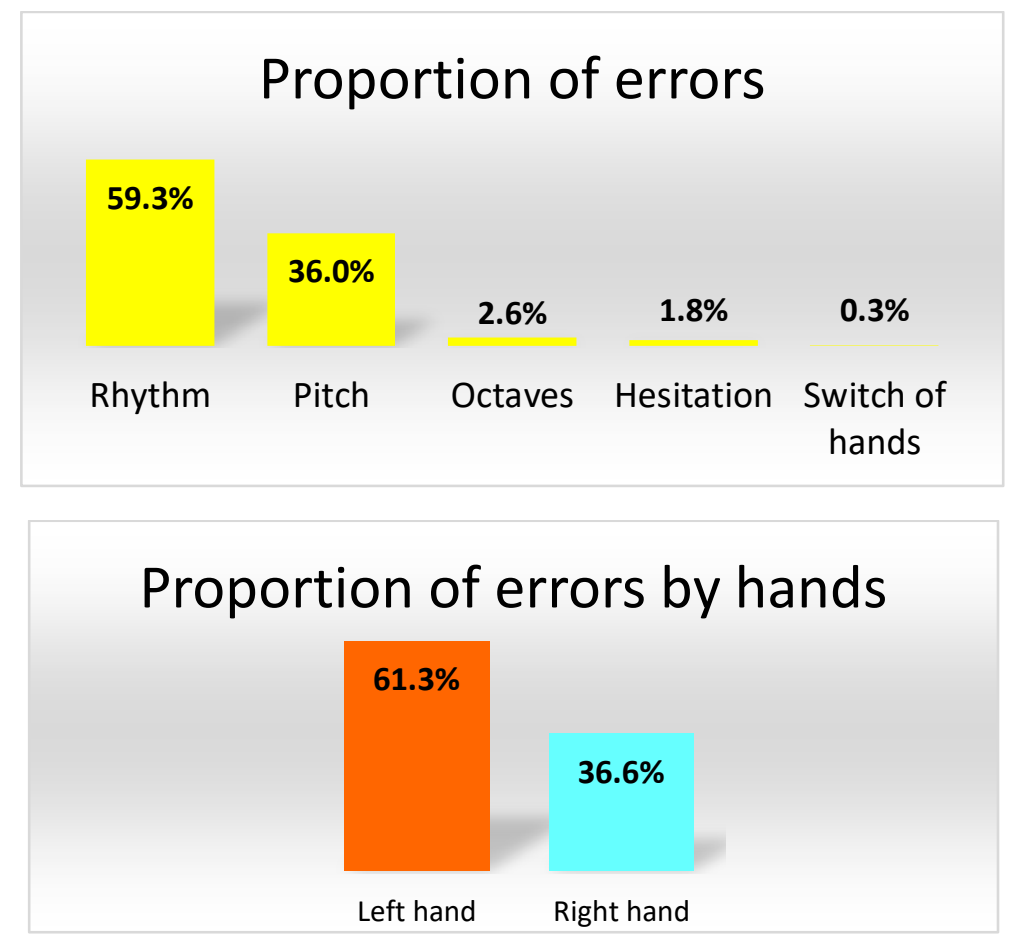

Graph 1 - Proportion of errors in rhythm, pitches, octaves, hesitation and switch of hands and laterality in relation to the total sum of errors.

At the top, Graph 1 shows that rhythmic and pitch errors were the most representative in the sample of this research. Together, they make up $95 \%$ of the errors in relation to the total errors made by the students. 
Octave errors, hesitation and switch of hands are unrepresentative and together total only $4.7 \%$. At the bottom, Graph 1 shows that $61.3 \%$ of the mistakes were made by the left hand and $36.6 \%$ by the right hand.

The number of errors in the modelling (called the dependent variable, criterion variable, response variable, or $y$ variable) will be presented as a result of adding or subtracting predictor variables (also called independent, explanatory, or $x$ variables). Predictor variables in this research are those that explain or interfere with the number of errors made by test participants. In general, the result of the EEGs can be synthesized from a generic formula, as presented in the next section.

\section{- Univariate modelling of the Predictor Intervention}

The Intervention variable is the most important predictor of this research, as it indicates if transposition had better results than the use of the four-hand repertoire and the rhythmic training. Overall, this predictor did not change anything in decreasing the number of rhythmic, melodic, left-hand, right-hand, and octave errors. This means that pedagogical interventions alone had no effect on the number of errors. Graph 2 shows the Intervention box plots and the error response variables in SR.

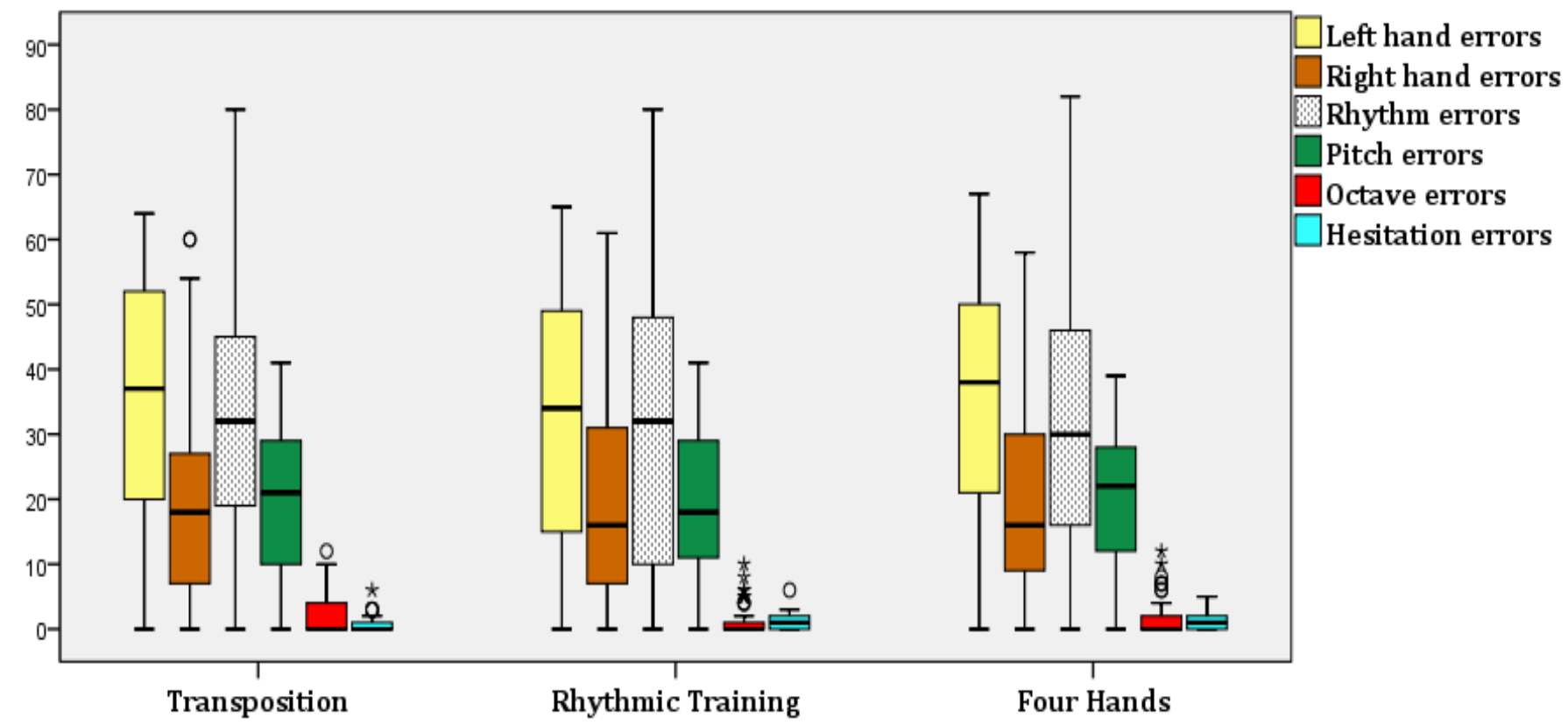

Graph 2 - Box plots of the predictor Intervention and the various types of SR errors of the response variables.

Box plots are used to visually assess the distribution of data. The above coloured rectangles contain $50 \%$ of the data set values. The position of the median line in the rectangles informs about the symmetry of the distribution, that is, a symmetrical distribution has its median in the centre of the rectangle and an asymmetric distribution will have the median below or above the middle position of the rectangle. In the example in Graph 2, one can compare the medians of each category separately. Visually, the four-hand, rhythmic training and transposition medians are about the same height when comparing the same error category with the $y$ axis. The chart also illustrates that there were more left-hand than right-hand errors, more rhythm than pitch errors, and more octave errors than hesitation. However, it is necessary to know precisely in numbers whether there was a differentiation between transposition, rhythmic training and four hands, and whether this difference was statistically significant. To this end, the univariate modelling of the predictor Intervention in GLMs was performed for all types of errors measured in this research, which are 
the errors in rhythm, errors in hesitation, errors in right and left hands, errors in octave and sum of total errors. Table 1 shows the data from the univariate exploratory phase: the intercept QICCS (M0), the model QICC when the predictor Intervention to MO is added, the marginal means of the categories and the $p$-values of the models resulting from this addition.

Table 1 - Marginal Means synthesis table, $p$-values of the predictor Intervention and QICCs.

Study of the predictor Intervention for Univariate Modelling

\begin{tabular}{|c|c|c|c|c|c|c|}
\hline \multirow[b]{2}{*}{ Response Variable } & \multicolumn{3}{|c|}{ Marginal Mean } & \multirow[b]{2}{*}{ p-values } & \multirow[b]{2}{*}{ QICC of M0 } & \multirow{2}{*}{$\begin{array}{c}\text { QICC of M0 + } \\
\text { Strategies }\end{array}$} \\
\hline & Transposition & $\begin{array}{c}\text { Rhythmic } \\
\text { Training }\end{array}$ & Four Hands & & & \\
\hline Rhythm Errors & 32,56 & 32,98 & 34,12 & 0,945 & 4298,167 & 4298,964 \\
\hline Pitch Errors & 20,49 & 19,51 & 20,44 & 0,927 & 1830,037 & 1831,533 \\
\hline Hesitation Errors & 0,70 & 1,21 & 1,11 & 0,048 & 326,497 & 318,266 \\
\hline Right Hand Errors & 19,49 & 21,30 & 20,73 & 0,892 & 3238,106 & 3235,36 \\
\hline Left Hand Errors & 35,53 & 32,23 & 35,15 & 0,807 & 3229,99 & 3218,486 \\
\hline Octave Errors & 1,98 & 1,05 & 1,31 & 0,183 & 870,553 & 849,644 \\
\hline Total of Errors & 55,77 & 55,09 & 55,11 & 0,966 & 5464,176 & 5465,109 \\
\hline
\end{tabular}

From the comparison of the three interventions - transposition, rhythmic training and four hands - it can be stated that transposition was no better than rhythmic training and the four-handed repertoire. The data show, like the box plots in Graph 2, that none of them performed better than another. There are three ways to verify this statement:

(a) the first form is the MO QICC, which indicates the average error of that specific model when only the intercept exists, i.e. when no predictor variable is added to the model. When adding the predictor Intervention to $\mathrm{MO}$, in some cases, the resulting QICC becomes higher than the MO QICC. This is the case for the response variables pace errors, pitch errors, total of errors sum. This increase determines that the presence of intervention causes more errors in the models than its absence.

(b) another important aspect is the visualization of the Marginal Averages of each Intervention. A simple look at the values of each of the response variables shows that the differences between them are minimal. Graph 3 visually shows these averages.

(c) finally, the $p$-values shown in the last column of Table 1 are the best reference for the effects of interventions on the number of errors, as they quantify that effect was a possible result of chance or the predictor variable under observation, in this case, the Intervention. A $p$-value less than 0.05 indicates that the predictor produced a statistically significant effect on that type of observed error. A $p$-value greater than 0.05 indicates that the effect produced was insignificant by that predictor. The data in Table 1 showed that $p$-values are greater than 0.05 in almost all response variables. The data confirms that transposition, rhythmic training and four-handed repertoire alone did not have any significant impact on any type of error. From this, we can conclude that students will continue to make errors greatly and none of these interventions alone will significantly decrease the number of such errors. Due to this innocuous profile of the predictor Intervention, it will not be presented in any of the following univariate models. In multivariate models, it will be presented only once to show the $p$-value above 0.05 of the model where it was added. A single exception to all this occurs in the Hesitation modelling of Table 1 , where $p=0.048$. This exception will 
be addressed in the section on data analysis of Hesitation modelling, where the additions and subtractions of the variables in their respective models will be shown.

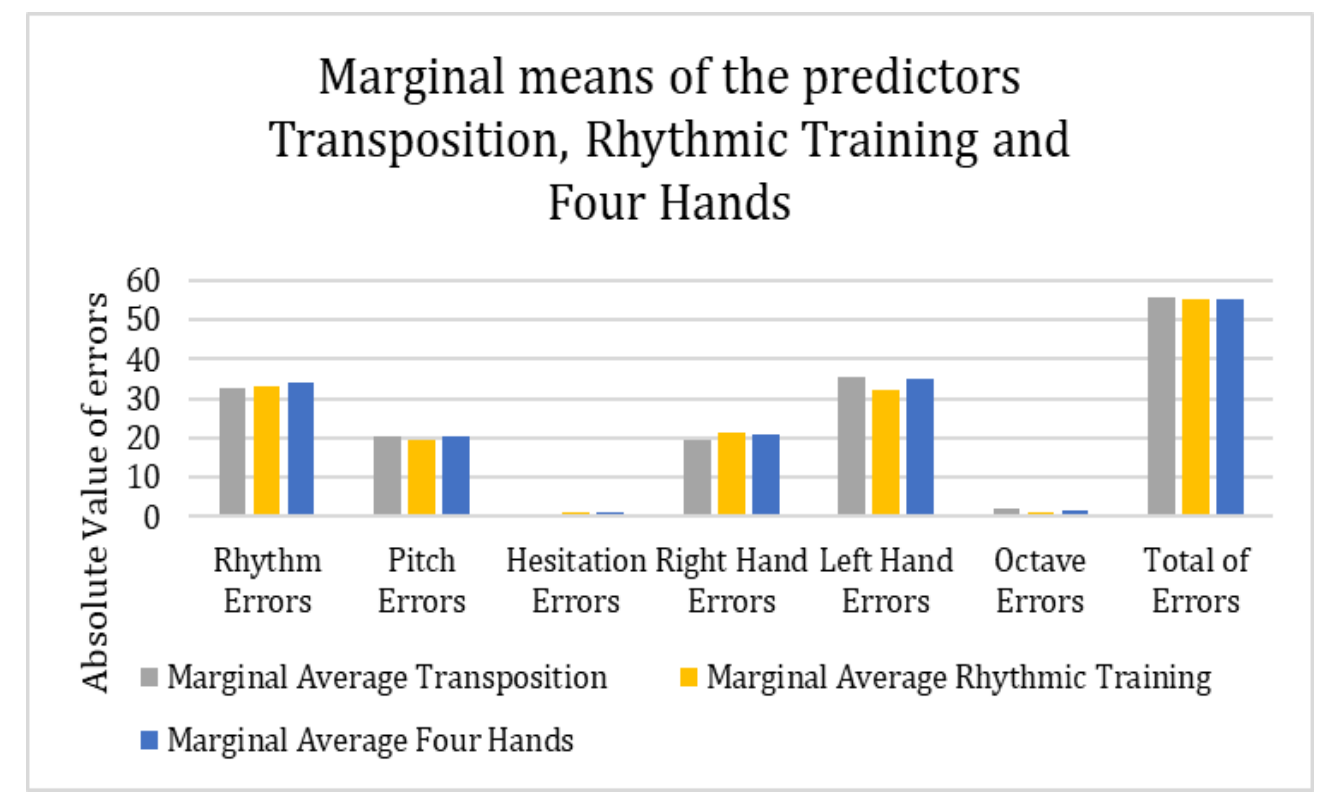

Graph 3 - Marginal means of the MO model in the predictor Intervention.

\section{Discussion of the most relevant model for pitch errors}

$M 17^{4}$ was the most relevant model for the response variable of the sum of pitch errors. The QICC was the second lowest of all models (QICC $=582,640$ ); $p=0.051$ for the model), leaving the $p$-value with its significance at the acceptance margins of $\mathrm{HO}$ (Table 2).

Table 2 - Test of Effects M17.

\begin{tabular}{|c|c|c|c|}
\hline \multicolumn{4}{|c|}{ Tests of effects of Model 17} \\
\hline & \multicolumn{3}{|c|}{ Type III } \\
\hline & \multicolumn{3}{|c|}{ Wald chi-square } \\
\hline Orign & & df & Sig. \\
\hline (Intercept) & 3152,347 & 1 & 0,000 \\
\hline Test & 6,983 & 2 & ,030 \\
\hline Level & 295,708 & 2 & 0,000 \\
\hline Harmony (Functions) & 4,821 & 1 &, 028 \\
\hline Instrument & 5,943 & 2 & 051 \\
\hline Average of weekly Study VIII & 7,234 & 2 & ,027 \\
\hline
\end{tabular}

Table 2 shows the M17 p-values with the Predictors Test, Level, Harmony I (Functions), Instrument, and Weekly Study Average VIII ${ }^{5}$, the ones that pedagogically performed best in terms of effects on total of pitch errors. Details on this interpretation will be given in the pedagogical interpretation at the end of this section.

\footnotetext{
${ }^{4}$ For more details of this modelling, see https://repositorio.ufmg.br/handle/1843/AAGS-AQQHE2 (from page 126 on).

${ }^{5}$ This number VIII indicates the eighty attempts of the 'instrument' category in the modelling process.
} 


\section{1 - Pedagogical interpretation of the most relevant model}

For teachers, what matters most in the pedagogical approach is the predictor variables in which they can act so that students have significantly fewer errors, or in choosing a variable in which teachers can manipulate to help to reduce them.

Regarding the Test variable, it is understood that the students' SR improved as a function of training, since the number of pitch errors decreased significantly in Test 2, although this improvement was not due to any transposition intervention, four-handed repertoire and rhythmic training. In Test 3, students made more mistakes than in Test 2 and this difference was not statistically significant. The difference between Tests 2 and 3 was in the quality of the repertoire, because the pieces of Test 3, although graded at the same levels, were not the same as in Test 1 . The pieces of Test 3 were modified in terms of tone and chromatic changes, but without changes in the rhythm and amplitude of the pentachord. This fact evidences, perhaps, that the students had more difficulty in reading notes of the pieces that were not of the same key learned in the classes, or that they had different chromatic changes from the ones they learned and, therefore, they made more mistakes in relation to Test 2. It can be understood that changes in pitches setting had more effect on errors compared to Test 2. The box plots in Graph 4 show students' performances according to the tests taken.

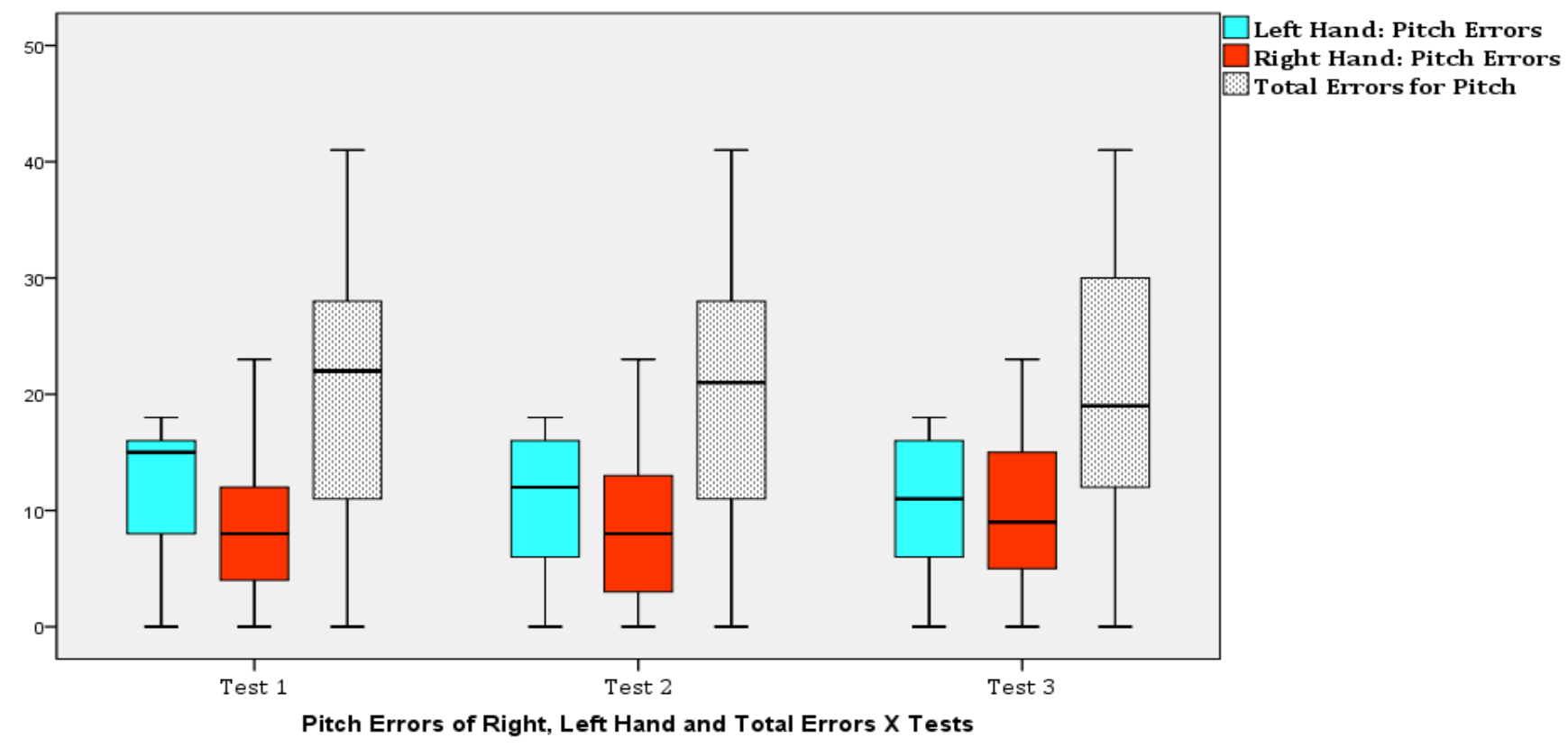

Graph 4 - Box Plots of Pitch Errors in the Predictor, Tests 1, 2, and 3.

The visual data from Graph 4 show that students missed more pitches on the left hand than on the right hand. The SR training (Tests 2 and 3) had more effect on the left hand than on the right hand. In the total of pitch errors, the training had less noticeable changes, as the median of the grey box plots were practically at the same heights.

Regarding the Level of the repertoire, the teacher should use, at the beginning of the SR learning, easier and simpler pieces, then the students will make fewer mistakes. This predictor shows that using a very difficult repertoire like Level 2 and Level 3 is useless, as students will make a lot of mistakes. It is important to balance the level of redundancy, novelty of the pieces and their challenge to a higher level. 
In the predictor Harmony I (right number of harmonic functions), knowledge of harmonic functions seems to contribute to better performance in pitch errors. In this sense, the teacher can act in the cognitive processing of learning. In the preliminary reading, for example, the student must identify harmonic chunking from chords, arpeggios, simple harmonic functions of tonic, subdominant, and dominant. This fact shows that there is a relationship between the pitches in order to connect them with the key apparently creating a different quality better than an SR centred on isolated notes. This fact of reading and relating what you see can be observed in the interviews, when students refer to the transfer of knowledge learned on the piano, and later applied to the visual perception of the scores in their respective instruments. In motor behaviour, the teacher can assist the student in assembling fingerings for the triads, in hearing the differences in major and minor keys, in performing the pentachord of that studied piece, as it was performed in the students' training phase.

In the Instrument variable, the positive betas of the predictor indicate that playing a different instrument did not decrease the number of errors, on the contrary, the errors increased. However, data from the M17 showed students who play the treble clef or melodic instrument have made more mistakes compared to those who play the clef melodic instruments. These data suggest to the teacher that a reinforced reading of the bass clef in the repertoire, proposing more exercises in both hands for this clef, may have effects on the reduction of the number of pitch errors.

Finally, as for the frequency of Weekly Study variable, M17 showed that it was relevant for the reduction of pitch errors. In other words, studying three times a week improves pitch errors performance significantly by 0.47 times. The teacher in this category can act to encourage the student to have many homeworks that can be studied more than three times a week, encouraging the student to study more often and to engage in SR activities.

\section{Discussion of the most relevant model for rhythm errors}

$\mathrm{M} 14^{6}$ was the most relevant model for the response variable of the sum of rhythm errors. The QICC was the lowest of all models (QICC $=1826.143 ; p<0.001$ ) for the model). See Table 3 .

Table 3 - Tests of Effects M14.

\begin{tabular}{lccc}
\hline \multicolumn{4}{c}{ Tests of effects of Model 14 } \\
\cline { 2 - 4 } & \multicolumn{3}{c}{ Type III } \\
\cline { 2 - 4 } & Wald chi-square & Sig. \\
\hline Orign & 2687,197 & 1 & 0,000 \\
\hline Intercept) & 41,030 & 2 &, 000 \\
Test & 122,244 & 2 & 0,000 \\
Level & 18,676 & 2 &, 000 \\
Average of weekly Study VIII & 28,976 & 2 &, 000 \\
Instrument & & & \\
\hline
\end{tabular}

Dependent Variable: Sum_Rhythm

Model: (Intercept), Test, Level, Average of weekly Study VIII

Instrument

\footnotetext{
${ }^{6}$ For more details of this modelling, see https://repositorio.ufmg.br/handle/1843/AAGS-AQQHE2 (from page 126 on).
} 
Table 3 shows that the predictors Test, Level, Weekly Study Average VIII and Instrument are the ones that pedagogically perform best in terms of effects on rhythm errors. Details on this interpretation will be given in the pedagogical interpretation at the end of this section.

\section{1 - Pedagogical interpretation of the most relevant model}

For the teacher, what matters most in the pedagogical approach are the manipulative variables in which he can act so that the students have significantly fewer errors. In this sense, the previous student's amount of time in studying instrument or music is not a changeable attribute that the teacher can use to help him.

As for the Test variable, the students' SR improved due to training, since the number of errors in rhythm decreased in Test 2 and Test 3, although this improvement was not due to transposition interventions, fourhands and rhythmic training. In Test 3, the students made more mistakes than in Test 2 . The difference between them was in the quality of the repertoire, because the pieces of Test 3 , despite being graduated in level, were not the same as in Test 1, they were modified in key and chromatic changes, but without changes in the rhythm and amplitude of the pentachord. This fact evidences, perhaps, that the students had more difficulty in reading pieces that were not the same key learned in the training, or that they had different chromatic changes from the ones they learned and, therefore, made more mistakes in relation to Test 2. Thus, the changes in pitch and rhythm settings had more effects on rhythmic errors in Test 3 than in Test 2. Students made more errors in rhythm than pitches and more in their left hand than in their right hand, as shown in the box plots in Graph 5.

As for the repertoire level, it is pedagogical to use at the beginning of SR learning easier and simpler pieces to make fewer mistakes. This predictor shows that using a very difficult repertoire like level 3 is useless, as students will make more mistakes. Again, it is important to balance the level of redundancy, novelty of the pieces and their challenge to a higher level.

At level 2, the biggest difficulty seems to be the simultaneity of the hands that requires more cognitive attention and more motor skills for better performance. This fact alone makes student performance difficult.

As for increasing the frequency of Weekly Study, the teacher can create more detailed homeworks to be performed on different days of the week, encouraging the student to study different pieces more than three times a week, as this frequency has more significant effects on decreasing rhythmic errors. Another important aspect is to promote any action that increases student motivation so that they become more involved in SR activities, encouraging them to study more than three times a week.

In the Instrument variable, the positive betas of the predictor indicate that playing another instrument does not decrease the number of rhythmic errors. However, the instrumentalist with bass clef reading does less than the others. The students who play the harmonic instrument misses 2.14 times more and the students who play the treble clef melodic instrument misses 1.9 times more compared to the reading of the bass clef. These data may inspire the teacher to reinforce the bass clef reading in the repertoire by proposing more exercises on both hands for that clef. Reinforcing this reading may decrease the number of rhythmic errors. 


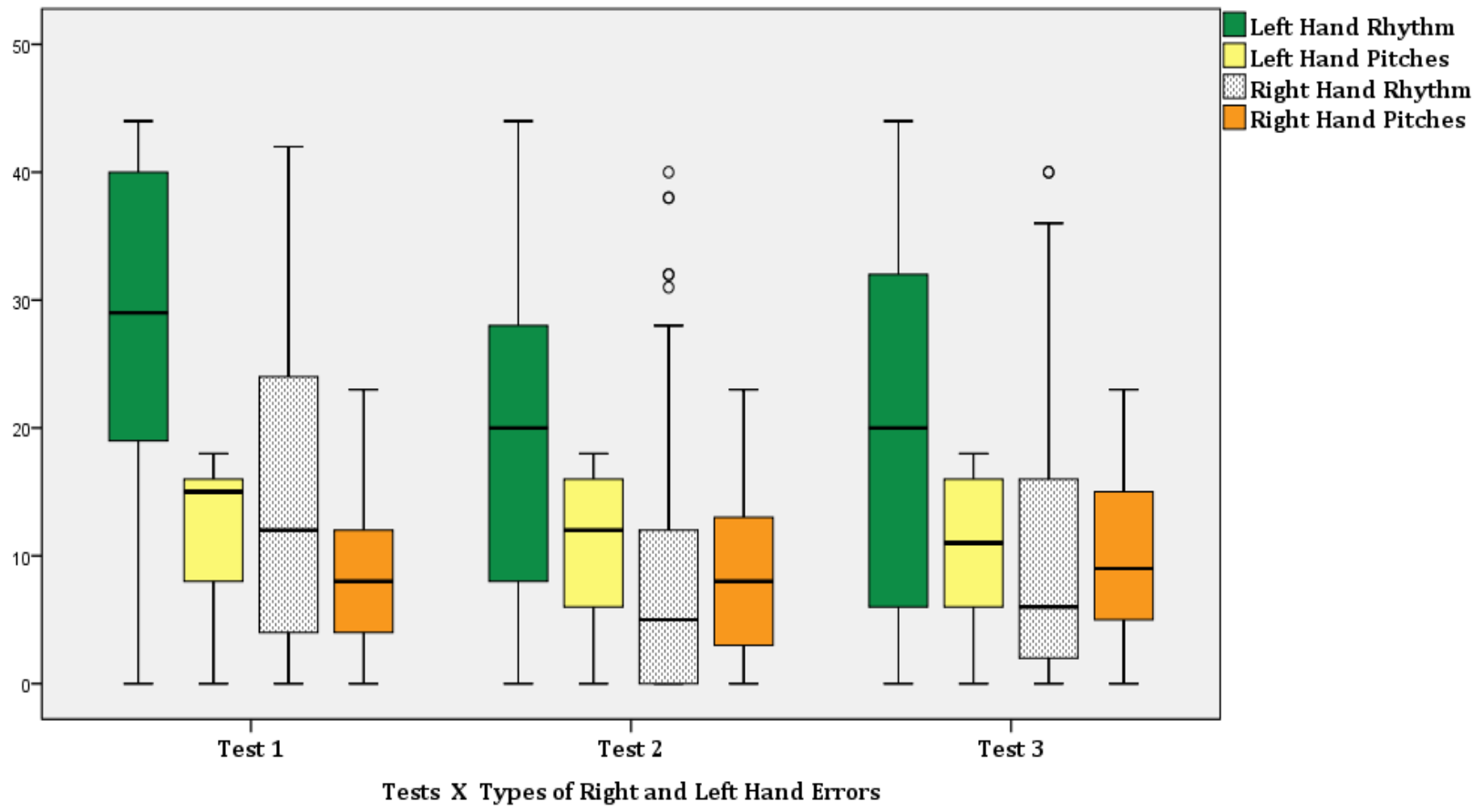

Graph 5 - Test X Types of Right- and Left-Hand Errors.

\section{Discussion of the most relevant model for the total sum of errors}

$M 14^{7}$ was the most relevant model for the Total Sum of errors response variable. The QICC was the fifth lowest of all models (QICC $=1908,835$ ) and $p=0.002$ for the model, as shown in Table 4.

Table 4 - Tests of effects M14.

\begin{tabular}{lrcc}
\hline \multicolumn{4}{c}{ Tests of effects of Model 14 } \\
\cline { 2 - 4 } & \multicolumn{3}{c}{ Type III } \\
\cline { 2 - 4 } \multicolumn{4}{c}{ Wald chi-square } \\
Orign & 4240,017 & 1 & 0,000 \\
\hline Intercept) & 52,401 & 2 &, 000 \\
Test & 195,062 & 2 & 0,000 \\
Level & 12,970 & 2 &, 002 \\
Average of weekly Study VIII & 13,650 & 2 &, 001 \\
Instrument & & & \\
\end{tabular}

\section{Dependent Variable: Total_Sum}

Model: (Intercept), Test, Level, Average of weekly Study VIII

Instrument

Table 4 shows the M14 p-values with the Predictors Test, Level, Music Study IV, Weekly Study Average VIII and Instrument that were the ones that pedagogically acted best in terms of effects on the total sum of students' errors. Details on this analysis will be given in the pedagogical interpretation at the end of this section. 


\section{1 - Pedagogical interpretation of the most relevant model}

The pedagogical aspects of the most relevant model predictors are centred on what the teacher can manipulate to reduce the number of students' total errors. In the Predictor Test, it is understood that students' overall SR improved as a function of training because the total sum of errors dropped significantly in Test 2, although this improvement was not due to transposition interventions, four hands and rhythmic training. In Test 3, students missed more than in Test 2. The box plots in Graph 6 show the performance of total hand errors separately according to the tests performed.

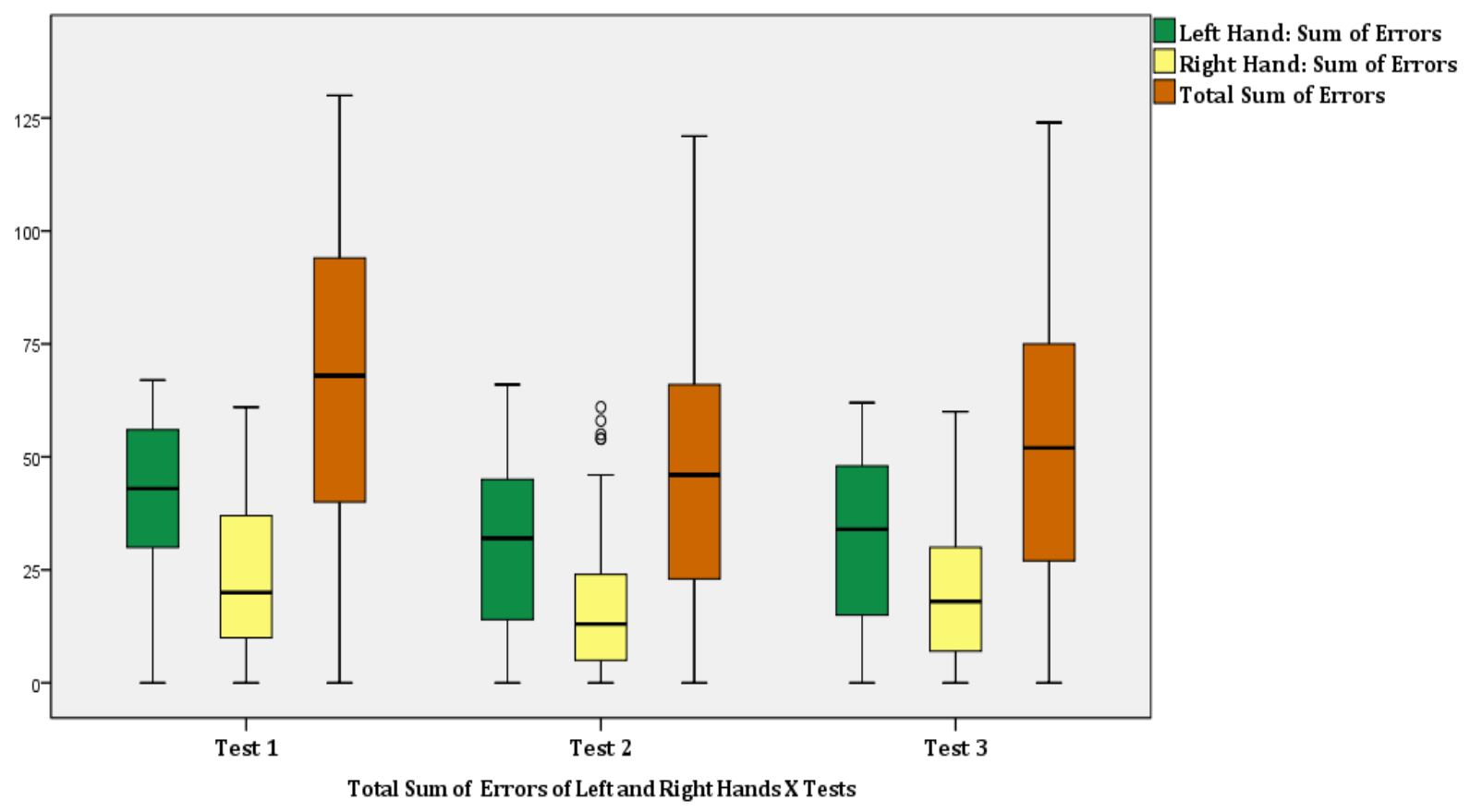

Graph 6 - Box Plots of Left Hand, Right Hand, and Sum Total Errors in Predictor Test.

The visual data from Graph 6 shows that students made more mistakes on the left hand than on the right hand. The training (Tests 2 and 3 ) had more effects on the left hand than on the right hand. In the total sum of errors, the training had more noticeable changes in Test 2 of the left hand. The right hand had few error decreases when compared in the three tests, as its medians in the yellow box plots have visually similar heights. In Graph 7, the box plots show the difference of the number of total errors in rhythm and test scores.

The visual data from Graph 7 show that students made more mistakes in rhythm than in pitches that, in blue box plots, have medians with visually similar heights. As for the repertoire level, at the beginning of SR learning, choosing easier and simpler pieces is essential to make fewer mistakes. This predictor shows that using a very difficult repertoire such as Level 2 and Level 3 can be useless, as students will make more mistakes. Once again, it is important to balance the level of redundancy, novelty of the pieces and their challenge to a higher level.

As for the frequency of Weekly Study VIII, M14 showed that it was statistically relevant for the reduction of total errors. In other words, students studying three times a week can improve their overall error performance. In this sense, the teacher can work on two ways: a) diversifying their activities in homeworks, creating a diversity oriented so that students can do SR more often; b) encouraging any pedagogical action that may deal with the student's motivation to be more interested, wanting to study and become more involved in SR activities. 


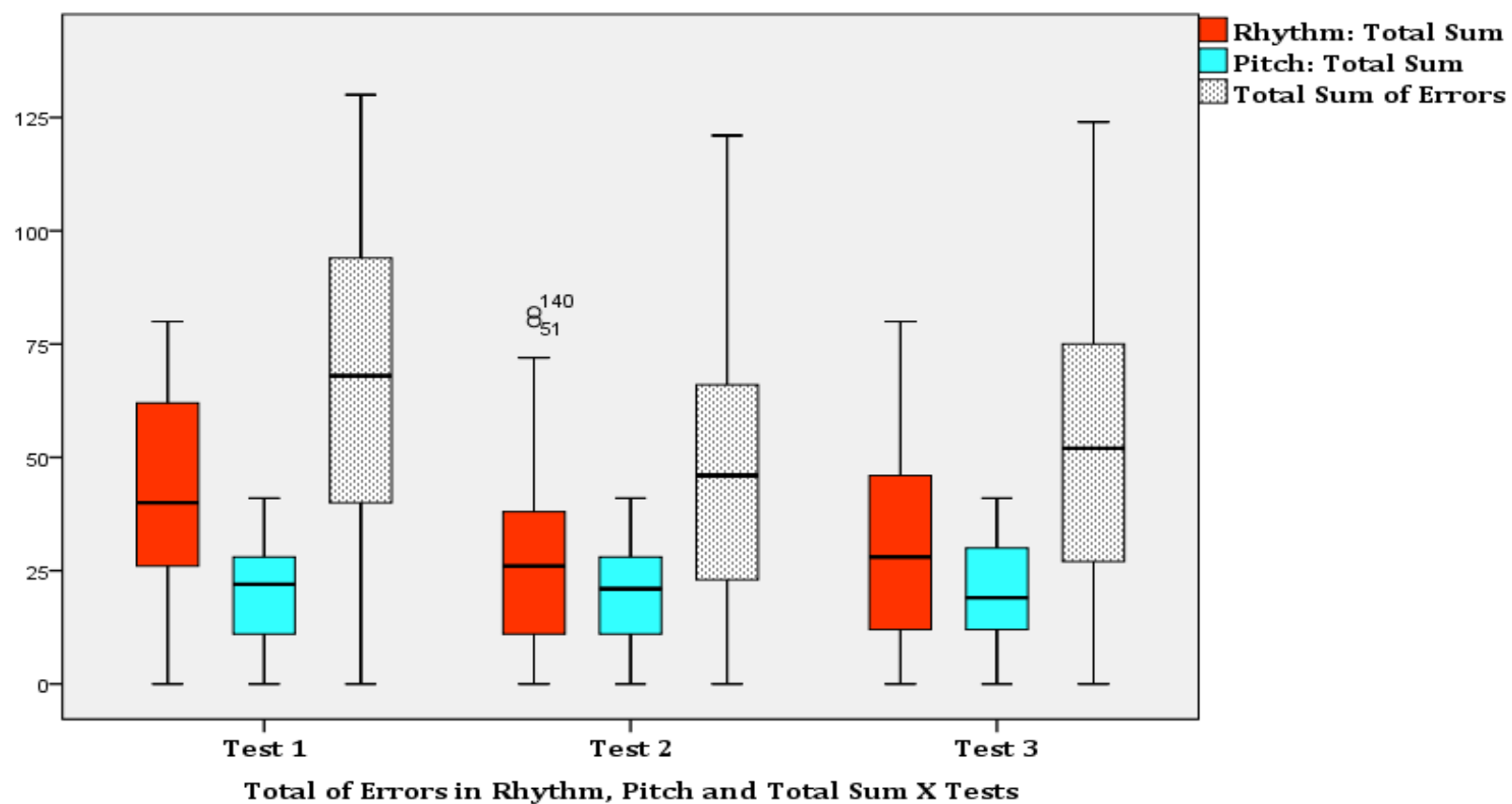

Graph 7 - Box Plots of Pace and Pitch Errors X Sum Total Errors in Predictor Test.

Finally, in the Instrument variable, the positive betas of the predictor showed, once again, that playing a different instrument did not decrease the number of errors, on the contrary, the errors increased. However, data from M14 showed that the student with bass clef reading was less wrong than the others. In this respect, teachers can produce more reinforcement in the reading of the bass clef in the repertoire. They can propose more exercises in both hands for this clef, with the intention of exercising this reading more especially in the students who are not familiar with it or who practice it less frequently, with the intention of reducing the total errors of the students.

\section{Summary of Quantitative Data Analysis}

To close the quantitative analysis, we synthesized all relevant models according to their types of errors in the response variables, exposing the negative and positive betas of their predictors, presenting the model's final QICC and their respective $p$-values. Table 5 summarizes the data.

Table 5 - Final summary of relevant models for the types of error of the response variables.

\begin{tabular}{|c|c|c|c|c|c|c|c|c|}
\hline & & \multicolumn{3}{|c|}{ Negative betas } & \multicolumn{2}{|c|}{ Positive Betas } & \multirow[b]{2}{*}{ QICC } & \multirow[b]{2}{*}{ p-value } \\
\hline Response Variable & Relevant Model & Predictor 1 & Predictor 2 & Predictor 3 & Predictor 4 & Predictor 5 & & \\
\hline Pitch Errors & M17 & Test & $\begin{array}{l}\text { Average of weekly } \\
\text { Study ( } 3 \times \mathrm{pw})\end{array}$ & $\begin{array}{c}\text { Harmony } \\
\text { (Functions) }\end{array}$ & Level & Instrument & 582,64 & 0,051 \\
\hline Rhythm Errors & M14 & Test & $\begin{array}{l}\text { Average of weekly } \\
\text { Study ( } 3 \text { x pw) }\end{array}$ & $\cdot$ & Level & Instrument & 1826,1 & 0,000 \\
\hline Hesitation Errors & M3 & Test & - & $\begin{array}{c}\text { Intervention } \\
\text { (Transposition) }\end{array}$ & - & - & 292,58 & 0,048 \\
\hline Total of Errors & M14 & Test & $\begin{array}{c}\text { Average of weekly } \\
\text { Study }(3 \times \text { pw })\end{array}$ & - & Level & Instrument & 1908,8 & 0,002 \\
\hline $\begin{array}{l}\text { Absolute } \\
\text { Frequency }\end{array}$ & - & 4 & 3 & 2 & 3 & 3 & - & - \\
\hline
\end{tabular}


The data in Table 5 showed two divisions of the predictors with statistical relevance to the modelling:

(a) with negative beta: the variables in this group have significant effects in decreasing the number of errors; the most frequent are Test and Weekly Study Average. The least frequent predictors are Harmony (Functions) and Intervention (Transposition) which have effects only to decrease errors in Pitches and Hesitation, respectively.

(b) with positive beta: the variables in this group have significant effects on increasing the number of errors: the most frequent are Instrument and Level. From these data, it can be understood that:

1. Predictor Test measured the effects of training on students who, in this research, had fewer errors in Test 2 than in Test 3;

2. the Average Weekly Study predictor measured the effects related to students' commitment to maintain a study throughout the training period; the models showed that the study of three times a week has significant effects in reducing all types of errors, except for Hesitation errors;

3. Predictor Level measured the number of errors as the difficulty of the repertoire increased; therefore, it always had its positive betas, because the harder the level, the more mistakes students will make;

4. the predictor Instrument signalled that all sampling musicians made mistakes of any kind, so their betas were always positive. However, musicians who have the bass clef reading on their original instruments (e.g. tuba, trombone, horn) are the least wrong compared to the other students.

With this data, piano teachers can develop various principles and strategies for improving his students' SR. These predictors of the relevant models are manipulable, dynamic and unfolding in pedagogical actions, in repertoire types, in diverse types of reading, in motivational issues, aiming to improve the performance of students who, in this study, achieved a reduction in mistakes.

\section{Conclusions of the experiment results in the response variables}

The analysis of the experiment data about the student's errors pointed out:

a) compared to total of errors, students made more errors in rhythm (59.3\%) than in pitches (36\%);

b) errors in hesitation, octaves and exchanging hands were not relevant in the overall calculation of the errors, since grouped together they only add $5 \%$;

c) the students made more mistakes in the left hand $(61.3 \%)$ than in the right hand $(36.6 \%)$;

d) after training, students improved $30 \%$ more in relation to the initial SR compared to the results of the total errors measured in Test 2; compared to Test 3, the development was $23.5 \%$ more;

e) from previous results on developmental rates, it can be concluded that students performed better in a known and practiced repertoire in training than in a unknow repertoire with a greater variety of keys and chromatic changes, suggesting that the transfer of learning to others musical contexts of pitch and rhythm were less successful due to the novelty factor;

f) the predictor transposition alone was not a more successful intervention than rhythmic training and the use of four-handed repertoire, except for hesitation errors only. Regarding rhythm errors, pitch errors and 
total errors, the result was the opposite of the expected, since none of the interventions performed better when compared to each other. It can be concluded that each of these predictors, alone, did not interfere in reducing the number of students' errors and, individually, are not good predictors for errors. These data contradicted what previous research had said about rhythmic training and the use of collaborative activities as good pedagogical strategies. One hypothesis to explain these results may be related to the students' low study frequency. Despite all this, they progressed in their SR from other variables detailed below.

g) the predictors that best explain students' mistakes in the context of undergraduate degrees at the UEMG School of Music were:

- for pitch errors: Test, Level, Harmony (Functions), Instrument and Weekly Study Average;

- for errors in rhythm: Test, Level, Weekly Study Average, Instrument;

- for errors in hesitation: Test and Intervention, in the specific case, transposition performed better than other interventions;

- for total errors: Test, Level, Weekly Study Average, and Instrument.

h) predictors that had no impact on student error were: Gender (male and female), Age, Laterality (righthanded, left-handed and ambidextrous), Years of Instrument Study, UEMG Course (LIM, LEM, different kinds of Music Teaching Course), Play by Ear, Chords (number of correct hits on rating), Years of Group Practice, Anxiety.

i) For the pedagogical planning in piano SR, it can be said that:

- practicing more sheet music readings on the bass clef (left hand) has beneficial effects in decreasing total errors;

- practicing more rhythmic rather than melodic exercises improves students' overall performance;

- practicing more on the left hand than on the right brings more benefits to SR performance;

- choosing a unique SR intervention has little effect on student development;

- the use of a hybrid curriculum matrix with three or more significant predictors seems to be the most appropriate route for SR competence, confirming current research by Zhukov et al. (2016) and Mishra (2016);

This research has resulted in breaking some myths. One is the belief that playing black keys is difficult and it should be learned after years of piano study. In contrast, students in the third class of the (experimental) transposition group at level 1 showed themselves that this practice is completely real and achievable. When performing simple pieces with five black keys, this practice also contradicted ABRSM's assumptions in level classification where this "difficult" key would only be learned from level 5 onwards.

The belief that practicing and mastering the performance of arpeggios, triads, pentachords, fingerings and, in extension, scales is useless for practicing the piano repertoire can also be criticized. On the contrary, the need to identify and practice these musical patterns separately in cognitive aspects and in motor training is imperative. Equally reprehended is the belief that simply reading a repertoire at a glance is enough to improve your SR. On the contrary, SR requires specialized and correctly oriented planning to be successful.

As a final conclusion, it can be stated that research in sight-reading can act substantially in building a competence in which knowledge, skills, attitudes and behaviours are needed, as seen in the introduction of 
this article. This research also revealed the demand for a specialized pedagogy for SR teaching. The Level variable measured in the experiment meant much more than a statistically easier or harder to perform repertoire. It carries an implicit conception of pedagogical choices, of a planned progressivity from technical difficulties, repertoire length, interval range of melodies, fingering, hand switching, selection of major and minor keys, presentation of markings, dynamics, agogics and their form of distribution, degree of interest, redundancy and variety of repertoire. The good intention in teaching and learning instrument performance is not enough to satisfy this particular pedagogy. Thus, it is necessary to have an exclusive planning of the strategies, the choice of the repertoire, the focus oriented to the cognitive processing and the motor behaviour.

This research also guided us to a broader understanding that the focus of the pedagogical action in SR, to be more effective, should not be oriented to the students, but to the teachers specialized in SR. Acting in the multiplier foci has better results than leaving them scattered in the learners' individual action. It is the teacher who has concerns about procedures, resources, approaches for developing a curriculum, as he is the conductor of this orchestra. It is the teacher who diagnoses the difficulties of the students, chooses the actions directed to improve the qualities and to solve the problems in such a complex musical competence.

Finally, this research reveals that, far beyond mistakes and hits in pitches, rhythms and hesitations, octave errors and switching hands, what teachers, students and researchers want is the spread of knowledge, skills and attitudes towards SR at the piano and the development of better skills and strategies for all participants in this musical setting.

Although the research has limitations due to the size of the sample and its local settings, which makes it impossible to generalize its results, it is hoped that it has contributed significantly so that researchers and educators can walk together in the convergence of common interests by minimizing the gap between them, making learning more complete and productive.

\section{References}

Halsband, Ulrike, Binkofski Ferdinand, and Max Camp. 1994. "The Role of the Perception of Rhythmic Grouping in Musical Performance: Evidence from Motor-Skill Development in Piano Playing." Music Perception: An Interdisciplinary Journal 11: 265-288.

Lehmann, Andreas C., K. Anders Ericsson, and Jack (editor) Taylor. 1996. "Performance without Preparation: Structure and Acquisition of Expert Sight-Reading and Accompanying Performance." Psychomusicology: A Journal of Research in Music Cognition 15: 1-29.

Mishra, Jennifer. 2015. "Rhythmic and Melodic Sight-Reading Interventions: Two Meta-Analyses." Psychology of Music 44 (5): 1082-1094.

Sampaio, Marcelo Almeida. 2017. As Estratégias Pedagógicas Para a Leitura à Primeira Vista Ao Piano. Doctoral Thesis, Belo Horizonte: Universidade Federal de Minas Gerais. https://repositorio.ufmg.br/handle/1843/AAGS-AQQHE2

Piano Specimen Sight-Reading Tests: ABRSM Grade 1. 2008. Vol. 1. 8 vols. London: ABRSM.

Piano Specimen Sight-Reading Tests: ABRSM Grade 2. 2008. Vol. 2. 8 vols. London: ABRSM.

Piano Specimen Sight-Reading Tests: ABRSM Grade 3. 2008. Vol. 3. 8 vols. London: ABRSM. 
Watkins, Alice Jan. 1984. The Effect of the Use of a Recorded Soloist as an Aid to the Teaching of SightReading Accompaniments at the Piano. Doctoral Thesis, Oklahoma (USA): University of Oklahoma.

Watkins, Alice, and Marie Adele Hughes. 1986. "The Effect of an Accompanying Situation on the Improvement of Students' Sight-Reading Skills." Psychology of Music 14 (October): 97-110.

Zhukov, Katie. 2014a. "Evaluating New Approaches to Teaching of Sight-Reading Skills to Advanced Pianists." Music Education Research 16: 70-87.

Zhukov, Katie. 2014b. "Exploring Advanced Piano Students' Approaches to Sight-Reading." International Journal of Music Education 32 (November): 487-498.

Zhukov, Katie, Liam Viney, Glenn Riddle, Arabella Teniswood-Harvey, and Kenji Fujimura. 2016. "Improving Sight-Reading Skills in Advanced Pianists: A Hybrid Approach." Psychology of Music 44 (2): 155-167. 